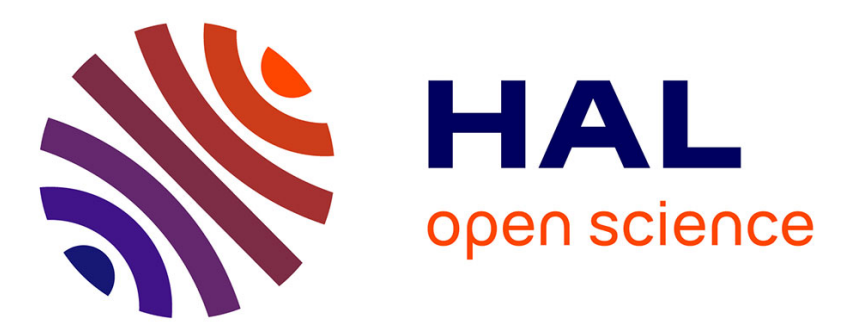

\title{
Handling differential mode conducted EMC in modular converters
}

\author{
Théo Lamorelle, Yves Lembeye, Jean-Christophe Crébier
}

\section{To cite this version:}

Théo Lamorelle, Yves Lembeye, Jean-Christophe Crébier. Handling differential mode conducted EMC in modular converters. IEEE Transactions on Power Electronics, 2020, 35 (6), 10.1109/TPEL.2019.2947735 . hal-02371762

\section{HAL Id: hal-02371762 \\ https://hal.science/hal-02371762}

Submitted on 13 Jan 2020

HAL is a multi-disciplinary open access archive for the deposit and dissemination of scientific research documents, whether they are published or not. The documents may come from teaching and research institutions in France or abroad, or from public or private research centers.
L'archive ouverte pluridisciplinaire HAL, est destinée au dépôt et à la diffusion de documents scientifiques de niveau recherche, publiés ou non, émanant des établissements d'enseignement et de recherche français ou étrangers, des laboratoires publics ou privés. 


\title{
Handling differential mode conducted EMC in modular converters
}

\author{
Théo Lamorelle, Student Member, IEEE, Yves Lembeye, Jean-Christophe Crébier, Fellow Member, IEEE
}

\begin{abstract}
This paper presents the analysis and management of differential mode conducted EMI in modular converters made from associations of standard conversion cells. Two main configurations, ISOP and IPOS are studied with the objective to define a generic EMI management technique, independent from the number of conversion standard cells implemented. First, analysis is carried out from a theoretical point of view based on simplified models. Second filtering solutions are introduced and compared. Especially, centralized versus distributed filtering techniques are compared with the objective to find generic solutions. The results are compared and validated with practical characterizations.
\end{abstract}

\section{INTRODUCTION}

Since the 1990's, modular converters based on Power Electronics Building Blocks (PEBB) are studied to simplify converter's design and implementation [1-2]. Converter's design and industrialization are long time processes due to the multi-physics and technological issues involved, including the prototyping and qualification issues. Among them, EMI signature and compliance are especially difficult to anticipate and require expertise, prototyping and very often tuning and reworks. This is not very convenient for modular converter implementations based on PEBB where the users are looking for plug and play solutions, independent from the configuration used.

PEBB converters are built by associating already produced, standardized, qualified and optimized conversion blocks. Similarly, modular multi-cell converters fulfill various specifications by networking standardized power conversion cells (CSC) [3]. The association of several CSCs, for multiplying power handling capabilities in terms of current and/or voltage ratings, induces also cumulative EMI disturbances. Even if the EMC signature of each CSC is addressed individually, ISOP (Inputs in Series - Outputs in Parallel) and/or IPOS (Inputs in Parallel - Outputs in Series) configurations modify the converter input impedance and produced disturbances. This paper investigates this issue with the aim to identify a simple and effective way to make invariant the signature of a modular converter, no matter the amount of conversion standard cells and the configuration in which they are implemented. The work focuses only on conducted differential mode disturbances to start with. The first part of the paper introduces in more details the purpose of this work. The second part focuses on the modeling of conducted EMI differential disturbances in modular converters while the third part is dedicated to the analysis. The last section is devoted to compare our theoretical work with experimental results based on a set of modular converters. $\mathrm{DAB}$ converters are used as conversion standard cells (CSCs) in all the work for many reasons listed in [4]. However, the whole analysis and conclusions can be transferred to any type of elementary and standardized conversion cell as long as it is a voltage input converter such as an $\mathrm{H}$ bridge converter or any converter with a DC voltage bus at the input terminals.

\section{DESIGNING MODULAR CONVERTERS FROM STANDARD CELLS}

As introduced before, modular converters are based on the association of pre-characterized and pre-defined conversion blocks or standard cells (CSCs). This association of CSCs fulfills global specifications Moreover, these CSCs are designed and qualified taking into account all the physical and technical constraints they must comply with. The implementation of a converter is then carried out by the association of several conversion cells (from a few units up to tens of CSCs). If well done, the characteristics and compliance of CSCs can be transferred to the whole converter in terms of, for example, efficiency, power densities, cost, standards compliance... Depending on the way they are associated at the inputs and at the outputs, four well known configurations are possible ISOP, ISOS, IPOS and IPOP. Considering that each CSC has a unity transformation ratio, the first configuration implements a step down DC converter, the following ones implementing respectively a larger current rating, a step up DC converter and finally a larger voltage rating. With a unique type of CSC, and by acting only on how they are associated, many converter specifications can be fulfilled.

The question is then how to mitigate the EMI signature of a modular converter made out of several units or teens of CSCs? How are transferred the EMI characteristics from the CSC level to the converter level? Two main options are possible. We can at first make CSCs to comply with regulation standards and then check how the compliance is affected by the numbers of cells implemented and the association type. This approach is based on a distributed management of EMI with filters in each CSC [5-7]. We can also consider that the EMI compliance is managed at converter level, once the CSCs are assembled [8-9]. In this case, the filters are centralized and can take care of all disturbances produced by all CSCs. Of course, another option can be a combination of both approaches, trying to minimize conducted EMI at CSCs level and also at converter level with some additional centralized filtering. The paper is focused on the analysis of differential mode conducted EMI management, trying to identify the best 
options to mitigate the EMI levels, in the most generic way, no matter the number of CSCs and their configuration.

The next section is dedicated to the modeling and the analysis of the differential mode conducted EMI of modular converters. Simple models are intended to represent, in the frequency domain and mainly for low order harmonics of the switching frequency, the signature of a single CSC and then the signatures of associations of CSCs in parallel or in series at the input of the modular converter. The aim is to identify the main behaviors especially related to the number of CSCs that can be implemented and how filtering strategies can be defined to mitigate produced differential mode EMI in modular converters, no matter the type of association and also the number of cells associated.

The CSCs considered in this work are based on traditional Dual Active Bridge (DAB) converter topology operated in phase shift control mode. To simplify and to optimize design issues, output voltage is considered close to input voltage as much as possible to minimize AC link inductance and maximize design factor [10]. It allows to reaching high efficiency and high power densities and to reducing as well differential mode disturbance levels. In figure 1, inductor $L_{A C}$ on the AC link is the key component for the design and the optimization of the DAB converter. The capacitor in series with $\mathrm{L}_{\mathrm{AC}}$ aims to block DC component in full bridge switching voltage. The resonance frequency of the LC dipole is much lower than DAB switching frequency so it is not a resonant $\mathrm{DAB}$ but a conventional phase shift $\mathrm{DAB}$ with temporal waveform presented in figure 1. Each converter cell includes, at the input and the output, decoupling capacitors $C_{\text {in }}$ and $\mathrm{C}_{\mathrm{o}}$ that are intended to filter the ripple current produced by each $\mathrm{H}$ bridge. Figure 1 provides idealized main time domain waveforms, the input current $\mathrm{I}_{\mathrm{DM}}$ of the converter and the $\mathrm{AC}$ link current $\mathrm{I}_{\mathrm{AC}}$ and the voltage across the $\mathrm{AC}$ link inductor $\mathrm{U}_{\mathrm{L}}=(+/-) \mathrm{V}_{\text {in }}(+/-) \mathrm{V}_{\mathrm{o}}$ depending on transistors switching sequence [11]. As shown on figure 1, the input current is periodic but its shape remains determined by the components and control signal which are not ideal. This is detailed in the following section.

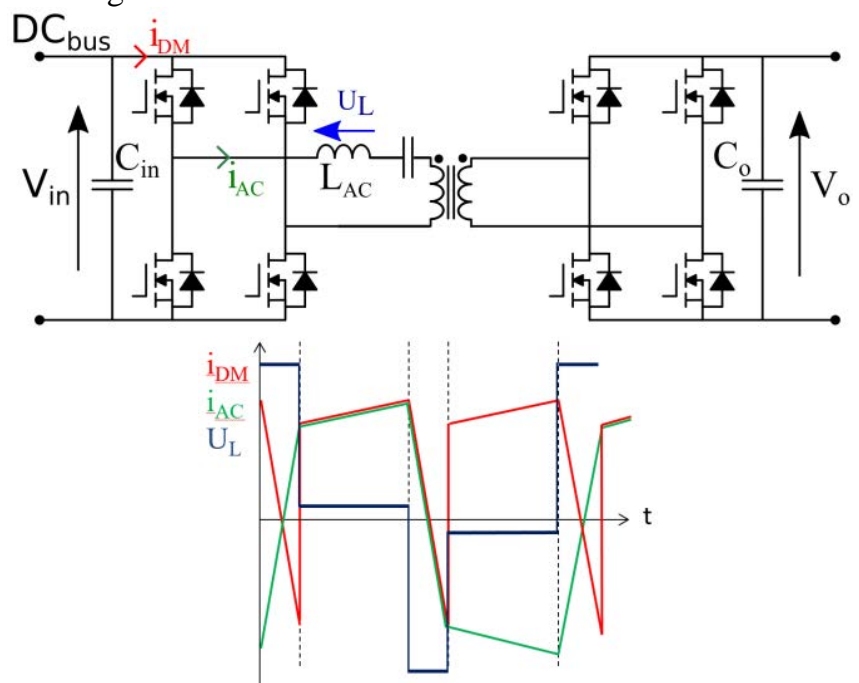

Fig. 1. DAB topology and typical DAB converter's voltage and current waveforms for $\mathrm{V}_{\mathrm{o}}<\mathrm{V}_{\mathrm{i}}$

\section{CONDUCTED DIFFERENTIAL MODE DISTURBANCE MODELING IN MODULAR CONVERTERS}

A Differential Mode (DM) current source $\mathrm{I}_{\mathrm{DM}}$ is used to represent the input current produced by one CSC. It is described in the frequency domain figure 2.b from the shape depicted in figure 2.a. For this input current shape, the operating conditions are $\mathrm{V}_{\text {in }}=10 \mathrm{~V}$ and $\mathrm{V}_{\mathrm{o}}=9.5 \mathrm{~V}$, average current is about $2 \mathrm{~A}, \mathrm{~L}_{\mathrm{AC}}=200 \mathrm{nH}$, switching frequency $\mathrm{Fs}=250 \mathrm{kHz}$, phase shift equals $6^{\circ}$. Especially, the two half cycle shape are considered slightly different to account for the non ideal switching transition time location over the period. Figure 2 presents a plot of the differential mode harmonics of the input current. This frequency domain representation will be used later to estimate, from a theoretical point of view, the magnitude of the harmonics currents across the LISN resistors after flowing through the filtering stage(s). Validity of this model is limited to the first order harmonics.

a)
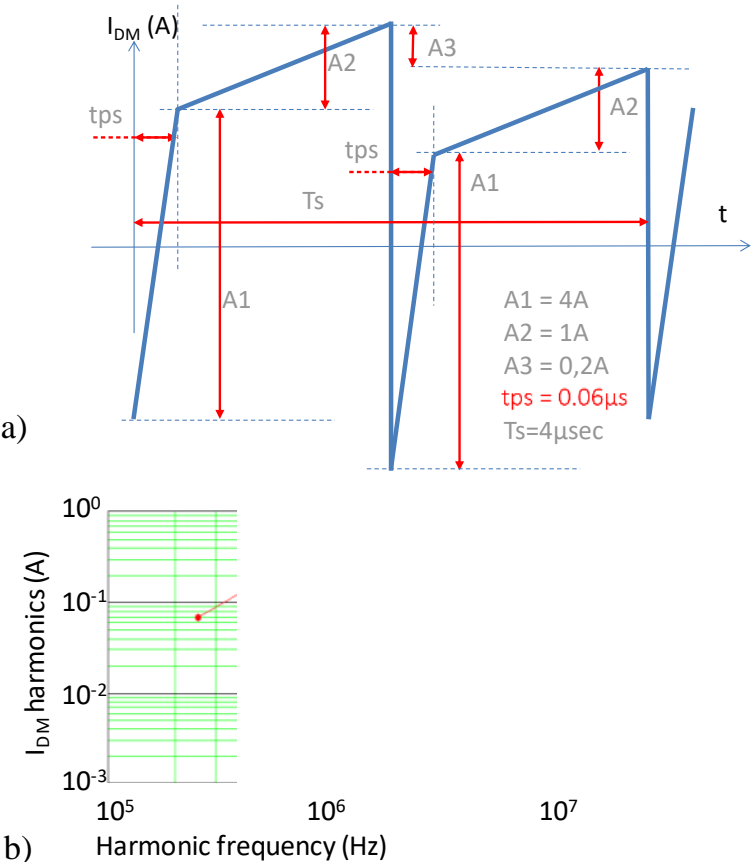

Fig. 2. Theoretical $I_{D M}$ current amplitude versus a) time domain and $b$ ) frequency domain representations for one CSC (all considered data for harmonics computation are made available on the figure).

As introduced in figure 2, handling conducted EMI in modular converters implies that CSCs must be optimized knowing that they are intended to be networked. The introduction and the design of the input filter at CSC and/or modular converter levels are going to be analyzed thanks to models. Figure 3 presents simplified equivalent models to study the converter differential mode harmonics signature depending on the type of association of CSCs (input series or parallel). A LISN is introduced here as a normalized source impedance to ease comparisons with respect to standards and to simplify comparisons with experiments in reproductive conditions. 


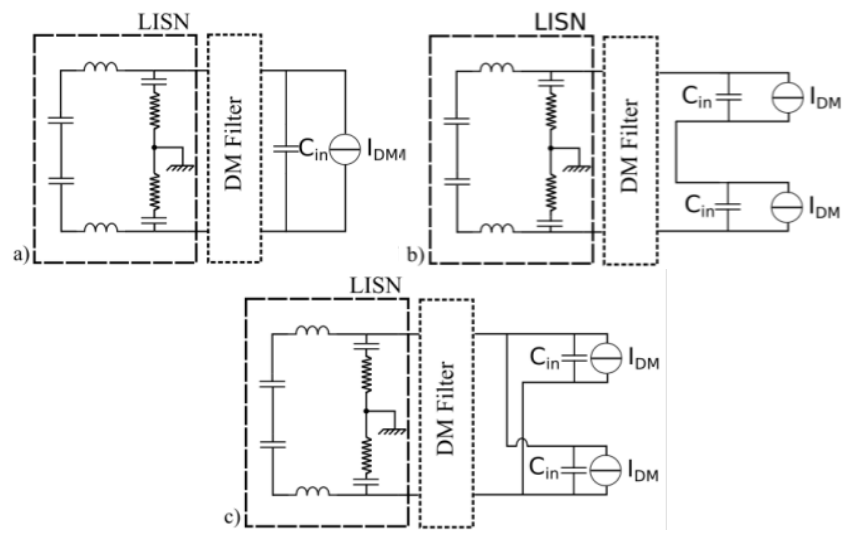

Fig. 3. Simplified equivalent models for studying EMI low order conducted differential mode harmonics. a) One CSC - b) Two CSCs implemented in series at their inputs - c) Two CSCs implemented in parallel at their inputs

In figure 3 , to represent in a simplified manner the conducted differential mode disturbances produced by the different configurations, each CSC is represented by its input capacitor $\mathrm{C}_{\mathrm{in}}$ and a current source representing the current $\mathrm{I}_{\mathrm{DM}}$ produced at the input $\mathrm{H}$ bridge of the DAB converter cell according to figure 1 . Only capacitor $\mathrm{C}_{\text {in }}$ is considered for now as the CSC distributed filter. Other types of filters will be presented in next part. Parallel and series associations of CSCs are studied, associating the equivalent models accordingly. In order to simplify at first analysis, all CSCs are considered identical and driven by the same controlling signals, i.e. without interleaving control strategy. In such a way, the current sources used in the models are all considered the same. At this stage, it is out of the scope of this work to consider, in more details, the modeling of the differential mode disturbance source as well as its propagation paths. It is clear that many parasitics should be considered for a more realistic modeling but this remains difficult to anticipate from a theoretical point of view. Indeed, parasitics are highly dependent on hardware implementation. From these simplified models, it is possible to analyze and to estimate the behavior for each association. It becomes also possible to define the characteristics of the DM filter that may need to be inserted between the LISN and the modular converter.

The two different associations' types are generalized in figure 4. When CSCs are series associated, the value of the equivalent capacitor filter at the input of the association is equal to $C_{i n} / n$, " $n$ " being the number of CSCs considered in the association. Differential mode current sources, all identical and in series, can be represented by a single current source, identical to the one in the model of one CSC. In the same way, a parallel association implies that the input capacitor is now multiplied by "n". Similarly, the differential mode current source must be multiplied by $\mathrm{n}$, since paralleling CSCs brings to put in parallel identical disturbance current sources.
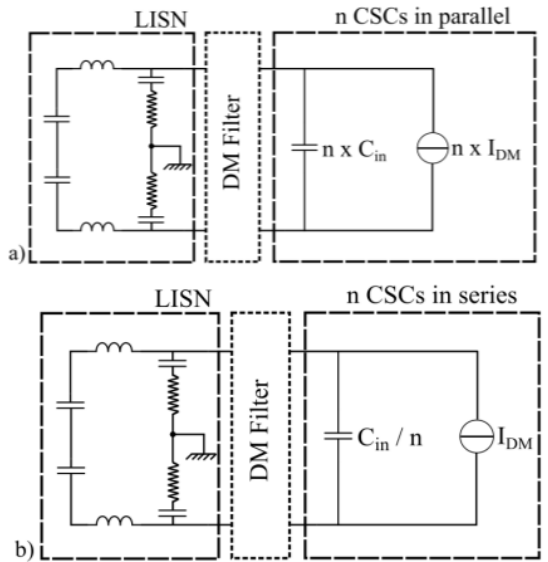

Fig. 4. Equivalent models for studying conducted differential mode disturbance including centralized EMI filter. a) CSCs in series - b) CSCs in parallel

In order to estimate the DM disturbance current levels flowing into the LISN, basic filtering architectures and propagation paths introduced in figure 4 are represented in the frequency domain with the computation of their current divider module with respect to frequency. Figure 5 is providing the module of the current attenuation versus frequency of the first order RC filters made out from the two LISN resistors in parallel with the input capacitor $\mathrm{C}_{\mathrm{in}}$ of a single CSC (red curve) or with the equivalent input capacitor for associations of 3,10 and $25 \mathrm{CSCs}$ in parallel or in series (green and blue curves). No additional DM filter is considered in addition to the basic components listed up to now.

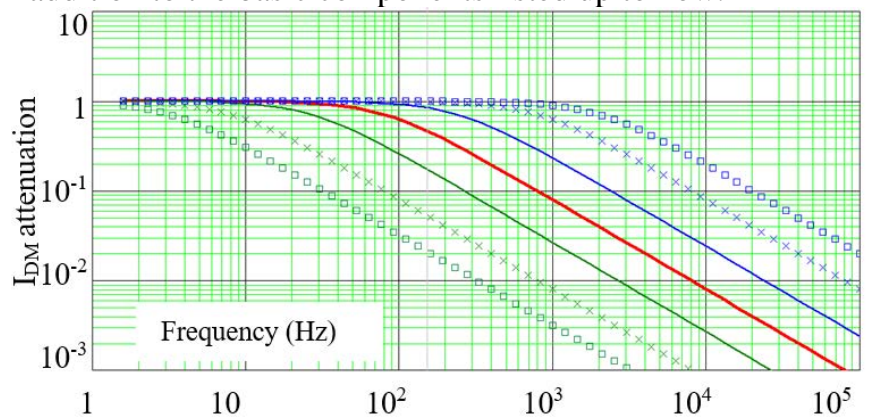

Fig. 5. RC filters attenuations versus frequency with $R=2 \times R_{\text {lisn }}=100 \Omega$ and Cin $=20 \mu \mathrm{F}$. red) one CSC - blue) $3(-), 10(\mathrm{x})$ and 25( $\square$ ) CSCs in series green) $3(-), 10(x)$ and 25( $\square)$ CSCs in parallel.

Multiplying filtering attenuations with the modules of the DM current harmonics provides LISN DM harmonic current levels. These harmonics can be compared with respect to the converter architecture or with respect to the standard limits in order to optimize the filtering needs. Based on these models, the paper focuses now on DM conducted EMI analysis. Figure 6 presents the estimated harmonics distribution in the LISN for one CSC operated in the conditions described in figure 4 and 5. This result is intended to provide a reference from which comparisons are made from the theoretical point of view. In a attempt to match with practical results later in the paper, the filter model also take into account the parasitic inductance in series with the $\mathrm{C}_{\mathrm{in}}$ capacitor with a value of $1 \mathrm{nH}$. 


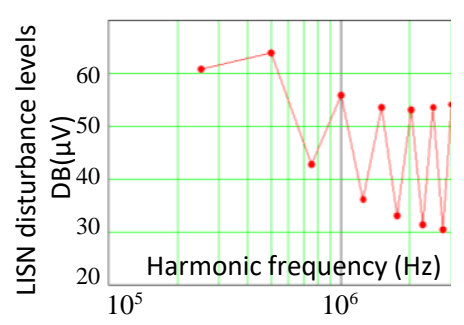

$10^{7}$

$10^{8}$

Fig. 6. Estimated frequency spectrum of DM disturbance levels across the LSIN resistor for one CSC modeled with the data displayed in figures 2 and 5.

\section{CONDUCTED DIFFERENTIAL MODE DISTURBANCES ANALYSIS IN MODULAR CONVERTERS}

This section is dedicated to analyze and to compare the behavior of associations of CSCs with respect to the number of cells implemented and with respect to the way they are interconnected at their inputs. Distributed filtering limitations are underlined depending on association type and the interest of centralized filtering is also investigated. As presented before, CSCs are represented with a DM current source $\mathrm{I}_{\mathrm{DM}}$ and an input capacitor filter $\mathrm{C}_{\mathrm{in}}$. This capacitor filter is characteristic to the simplest distributed topology filter. Figure 7 introduces several other filters architectures that can be considered and compared with respect to their location, centralized or distributed. Some others and more complex topologies can be studied but this paper will only deal with the presented one.

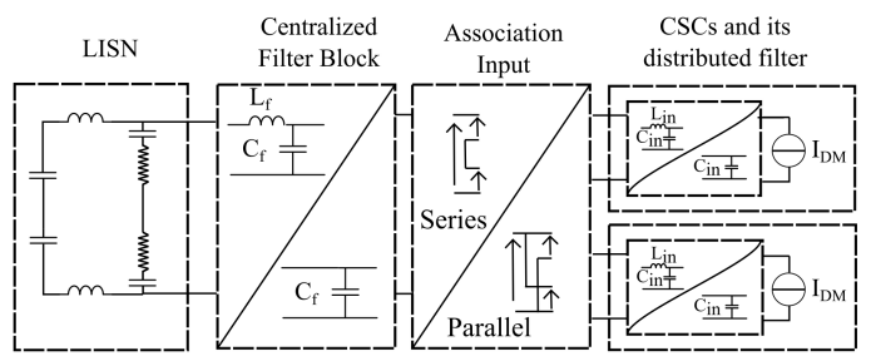

Fig. 7. Different DM filtering architectures and locations (centralized versus distributed)

\section{A. Input series associations:}

Considering only $\mathrm{C}_{\text {in }}$ input capacitor at the entrance of each CSC and without adding any filter, centralized or distributed, looking at figure 5, it appears that the series association of CSCs produces a significant reduction in filtering attenuation with respect to the number of conversion cells implemented (blue curves). Indeed the filter corner frequency is highly dependent on filter capacitor value which is influenced on the number of CSCs implemented. This means that this configuration will require a post assembly evaluation of conducted DM EMI signature in order to check and to optimize filtering needs to comply with standards.

Considering distributed filters, a second order filter can be built at the entrance of each CSC, adding an input filter inductor $\mathrm{L}_{\text {in }}$ together with the decoupling capacitor $\mathrm{C}_{\text {in }}$ already in place in each CSC. The produced conducted EMI filtering attenuation at CSC scale can be significant but it requires a large value for the inductor if effects on low order harmonics are targeted as it can be seen in figure 8 . This is mainly due to the fact that the filtering inductor $\mathrm{L}_{\text {in }}$ is directly connected in series with the LISN resistors. Being distributed over the CSCs' series association, the second order filter suffers from the same issue as the first order filter between the first (between 100 and $1 \mathrm{kHz}$ ) and second cutoff frequencies (around $100 \mathrm{kHz}$ ) in figure 8 . In this frequency range, the filter attenuation remains invert proportional to the number of CSCs implemented in series. On the other side, above the second cutoff frequency, the series association of the distributed inductors provides a positive effect as it can be checked in figure 8 with the blue curves for 3 and 10 CSCs implemented. To conclude, distributed over each CSC first and/or second order EMI filters are not a satisfactory solution for systematic mitigating conducted EMI in series associations of CSCs with respect to standards.

Complementary to distributed filtering solutions analysis, centralized filters can be studied. A centralized input inductor can be added at first to implement a second order filter with one more component. It would produce similar results as analyzed just above when CSCs are associated in series. To keep EMI levels under the limit, the value for that centralized inductor would have to be set accordingly to the number of cells in the series association which is not an option for generalization.

If a centralized filter capacitor $\mathrm{C}_{\mathrm{f}}$ is added to the series association of CSCs with only $\mathrm{C}_{\text {in }}$ input filter, the DM first order filter is now made out the LISN resistors in parallel with $\mathrm{C}_{\mathrm{f}}$ in parallel with $\mathrm{C}_{\mathrm{in}} / \mathrm{n}, \mathrm{n}$ being the number of cells associated in series. In that case, the filter attenuation is kept almost stable with respect to frequency no matter the number of CSCs implemented thanks to the addition of Cf. It is important to note that the additional capacitor must withstand the total input voltage in case of series associations of CSCs. Additional filter inductor $\mathrm{L}_{\mathrm{f}}$ can be added between $\mathrm{C}_{\mathrm{f}}$ and LISN to produce additional filtering for the upper frequency range without being affected by the number of CSCs implemented. Furthermore, all filtering components added between $\mathrm{C}_{\mathrm{f}}$ and LISN will produce a centralized attenuation to the whole modular converter, leading to a generic and effective EMI filter solutions.

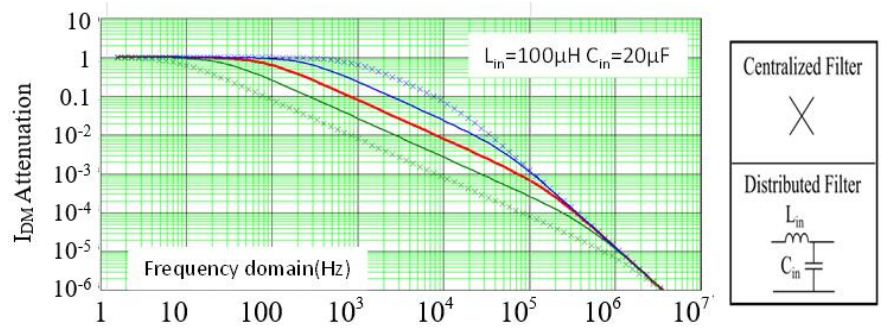

Figure 8. EMI filters attenuation for second order distributed filters implemented in each CSC for 1 CSC (red curve), 3 and 10 CSCs and for series (blue curves) and parallel (green curves) associations.

\section{B. Input parallel association:}

The same analysis can be carried out for CSCs parallel associations. Considering only $\mathrm{C}_{\text {in }}$ input capacitor at the entrance of each CSC, looking at figure 5, it appears that the 
input parallel association of CSCs produces a significant positive change in filtering attenuation with respect to the number of conversion cells implemented. This additional filtering will compensate for the cumulative $\mathrm{I}_{\mathrm{DM}}$ sources with respect to the number of CSCs in parallel, leading to stable and generic DM EMI spectrum no matter the number of cells. This means that, from a theoretical point of view, this configuration will not require a post assembly evaluation of produced DM EMI.

If a second order filter is built at the entrance of each CSC to improve filtering effects, adding an input inductor Lin, the produced filtering attenuation at CSC scale is significant in the upper frequency range. Being distributed over the CSCs' parallel association, the second order filter suffers from equivalent paralleling of input inductors. As a result, the second order filtering is impacted by the amount of CSCs associated in parallel. This can be checked in figure 7 with the green curves. The $40 \mathrm{~dB} / \mathrm{dec}$ attenuation is kept identical over the frequencies no matter the number of CSCs. Therefore, the cumulative IDM will produce increasing DM EMI level in the upper frequency range with this type of filter and this type of association. Distributed second order filters are not a satisfactory solution for systematic mitigating EMI in series associations of CSCs.

It is also interesting to look the impact of centralized filters in the case CSCs are implemented in parallel. If only a centralized capacitor is added to the parallel association of CSCs, the filter attenuation is kept almost constant no matter the number of CSCs implemented. Especially, this configuration will produce the same attenuation no matter the number of cells in parallel or in series. On the other side, it is important to note that the additional capacitor would have to withstand more EMI currents in case of parallel associations of CSCs.

The centralized association of an inductor would produce also a significant EMI reduction but its current rating would be highly dependent on the number of cells. An additional with the cumulative value for $\mathrm{C}_{\mathrm{in}}$, the second order filter made out a centralized inductor $\mathrm{Lf}$ and $\mathrm{C}_{\mathrm{in}} \mathrm{Xn}$ would cancel the cumulative IDM produced when CSCs are associated in parallel. After the centralized inductor, centralized capacitors and inductors can be added without being affected by the number of CSCs associated in parallel.

\section{Comments and guidelines:}

Based on the previous analysis, if we are looking for the most generic EMI filter architecture, a centralized $\mathrm{C}_{\mathrm{f}}$ capacitor followed by any second or third order filter between $\mathrm{C}_{\mathrm{f}}$ and LISN is the most suitable solution. In that case, no matter the series or parallel association and the number of cells implemented, the produced disturbance levels will be the same. In such a way, CSCs can be assembled regardless EMI issues if the distributed EMI filter has been initially correctly designed to attenuate the differential mode harmonics with respect to regulations. It is important to note that the centralized filter will still need to consider voltage and current ratings at the entrance of the modular converter. As a consequence, this analysis does allow us to defining a fully generic centralized filter from the value point of view but not from the component rating point of view. This of course remains dependent on the configuration type and CSCs numbers, this will be not the case for the component ratings.

\section{EXPERIMENTAL RESULTS}

The practical experiments were carried out considering only in differential mode disturbances. Test setup is presented on figure 9. The test bench is set as follows: A LISN is placed between DC source and networked CSC to filter any disturbance coming from the power supply or the network. In our case, since we are not characterizing common mode (CM) disturbances, the ground plane, required for normative measurements [EN55022] has been removed to reduce as much as possible CM currents flowing through the LISN. The spectrum analyzer is connected across one of the LISN measurement resistor. The spectrum analyzer used throughout this paper is R\&S® FSVA/FSV. Figure 9 is depicted a picture of the bench and the analyzer. All measurements are depicted in $\mathrm{dB} \mu \mathrm{V}$ to enable future comparison with EN55022 standards. This standard provides the peak values not to be exceeded and the average values of the electromagnetic spectrum. We focus on the 55022 Class A standard. Only the maximum values will be plotted in this paper in accordance with this standard. Concerning the devices under test (DUT), the tests are conducted on one, three and six CSCs associated at their inputs in series or in parallel and with distributed and centralized filters. Figure 9 shows pictures of CSCs. The results can then be compared with the theoretical analysis provided above in a tentative to validate them. Moreover, the CSCs' network needs a control block to generate control signals. A power supply block is needed to control block. All of these blocks could be supplied by an external DC power supply. In this experiment, the control part and its own power supply are supplied through the LISN in order to get more realistic results. As a result, all spectral measurements include power supply and micro-controller differential mode EMI signature. An initial DM EMI measurement has been carried without CSCs operation to check for the produced disturbances coming from the control part and its own power supply. This is depicted figure 9 hereafter. As it can be seen, the EMI produced by the auxiliary devices are $40 \mathrm{~dB} \mu \mathrm{V}$ at $250 \mathrm{kHz}$ and above. As it will be shown later, these contributions are significantly lower than the one produced by the CSCs and can be neglected.

a)

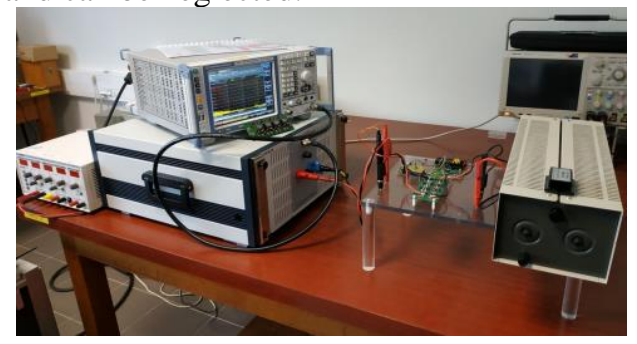




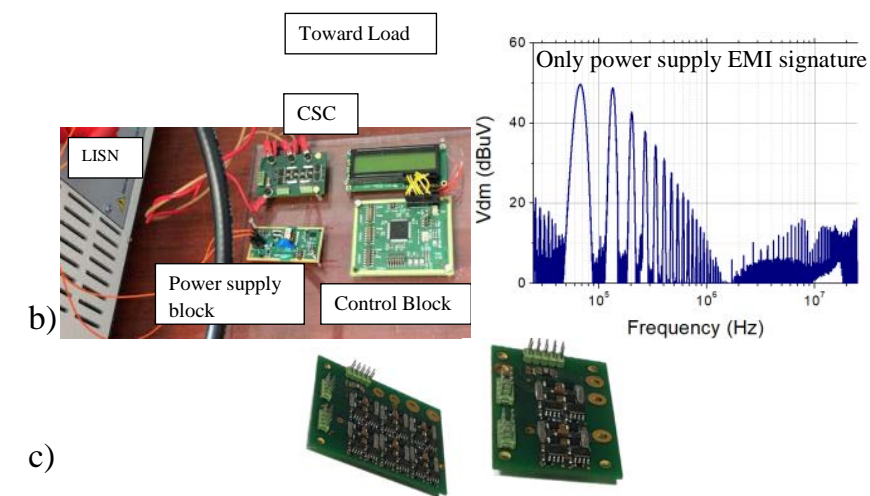

Fig. 9. a) Setup test bench for EMC differential mode conducted EMI characterization. b) Left: focus on setup test bench; Right: control part and its supply DM EMI signature. c) Pictures of one CSC and three CSCs.

In order to achieve comparable results, operating procedure has to be described. Each experience is done with, as much as possible, same operating conditions and electrical parameters at CSC level: same switching frequency, same phase shift, same input and vutput voltages and currents ... One important thing is to respect electrical level on each CSC in order for them to produce almost identical DM disturbances. As a result, the main power supply and the load are set accordingly depending on the configuration that is under test. If CSCs are association and series at their inputs, the input supply must be set 3 times higher than when a CSC is characterized alone.

Each CSC is operated at $10 \mathrm{~V}$ input voltage and delivers $9.5 \mathrm{~V}$ to a resistive load. In addition, the CSC is supposed to have a $2 \mathrm{~A}$ DC input and output current ratings. Both, current and voltage ratings produce a significant impact on differential mode EMI, since the current rating will directly affect the magnitude of the first orders high frequency harmonics and the input and output voltage will affect the shape of the input current, which in turns will impact also on the magnitudes of the first orders harmonics multiples of the switching frequency.

Three experiments are presented in the following part of this paper. Each experience is done considering a decoupling capacitor $\mathrm{C}_{\mathrm{in}}=20 \mu \mathrm{F}$ at the input of each CSC, acting as a first order distributed filter. The addition of a centralized filter capacitor is also considered with the objective to implement only first order filters and to check if combining distributed and centralized filtering scheme, the low order differential mode harmonics can be considering independent from the CSC number and configuration.

Special attention should be paid to all the following experimental figures. Since the spectrum is measured at the converter input, when supplied through the LISN, the frequency of the 1 st harmonic should be set at twice the switching frequency. Indeed, the single phase inverter produces, each switching cycle, the same current shape every half period. Therefore, in theory, if the two half period current waveforms are strictly the same, there should not be odd harmonics, multiple of the switching frequency. Since the switching frequency is $250 \mathrm{kHz}$, the harmonics depicted on next figures should only be $500 \mathrm{kHz}$ harmonics and their multiples $(500 \mathrm{khz}, 1 \mathrm{MHz}, 1.5 \mathrm{MHz}, \ldots)$. However, on the following figures (10-13), it is possible to see multiple lines of $250 \mathrm{kHz}(750 \mathrm{kHz}, 1.25 \mathrm{MHz}, \ldots)$. These harmonics are still visible because they represent the non fully symmetrical behavior of the inverter stage as it has been explained in section III and illustrated in figure 2. Depending on the shape on the $\mathrm{H}$ bridge current, this can produce random contributions that become non negligible. The difficulty is then that from one CSC to the other, it is not predictable how the mismatch occurs and its magnitude. As a result, the whole approach is not applicable to those harmonics, odd multiple of the switching frequency. This will have to be fixed since those harmonics have quite significant magnitude. For the purpose of the work, the reader is asked not to focus on odd harmonics but to look after even harmonics where it is actually possible to check for the behavior of the approach in practice. Besides, all $\mathrm{HF}$ harmonics which are placed before $250 \mathrm{kHz}$ refers to the auxiliary power supply EMC spectrum showed in figure 9. As a consequence, next results are showing the whole spectrum and zooms are provided only on $500 \mathrm{kHz}$ and $1.5 \mathrm{MHz}$ harmonics for each configuration.

Figure 10 presents the DM conducted signature for one, three and six CSCs connected in parallel at their inputs, with synchronized and identical control signals.

The two first odd harmonics multiple of twice the switching frequency are depicted in more details. It clearly shows that differential mode EMI contributions for the three configurations produce are almost comparable, without the need to add additional filtering. This is good news and seems to validate that the DM EMI levels obtained at CSC level can be transferred to converter level if CSCs are associated in parallel, at least for the low order harmonics. Looking at the global spectrum, one can see that this is not totally the truth for other low order harmonics. We had difficulties to tune properly the other harmonics, which are very sensitive to the operating point of each CSC.

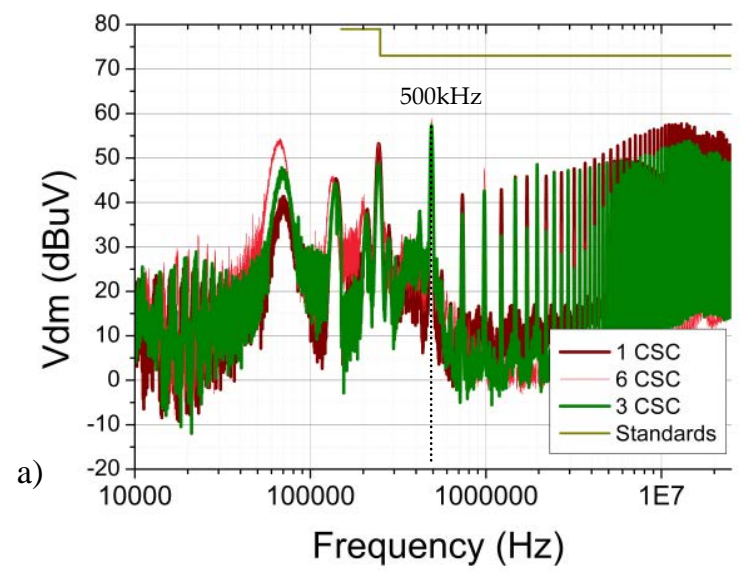




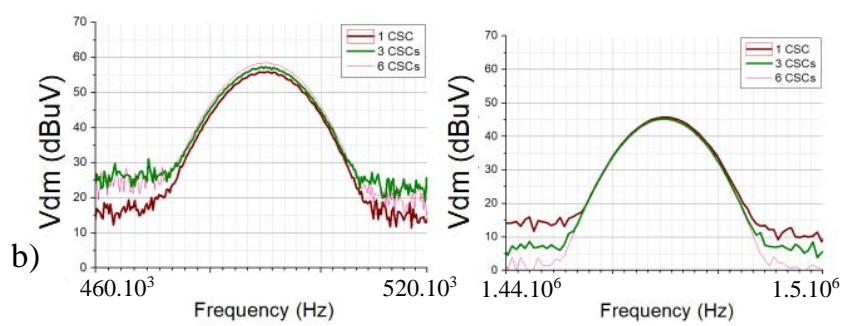

Fig. 10. Differential mode EMC spectrum for one, three CSC and six CSCs in parallel association with only input filter $\mathrm{C}_{\mathrm{in}}$, distributed on each CSC - LISN $\mathrm{V}_{\mathrm{DM}}$ measurements with a) full frequency range $\mathrm{b}$ ) focus on $500 \mathrm{kHz}$ (left) and $1,5 \mathrm{MHz}$ (right). Standards used is EN55022 Class A
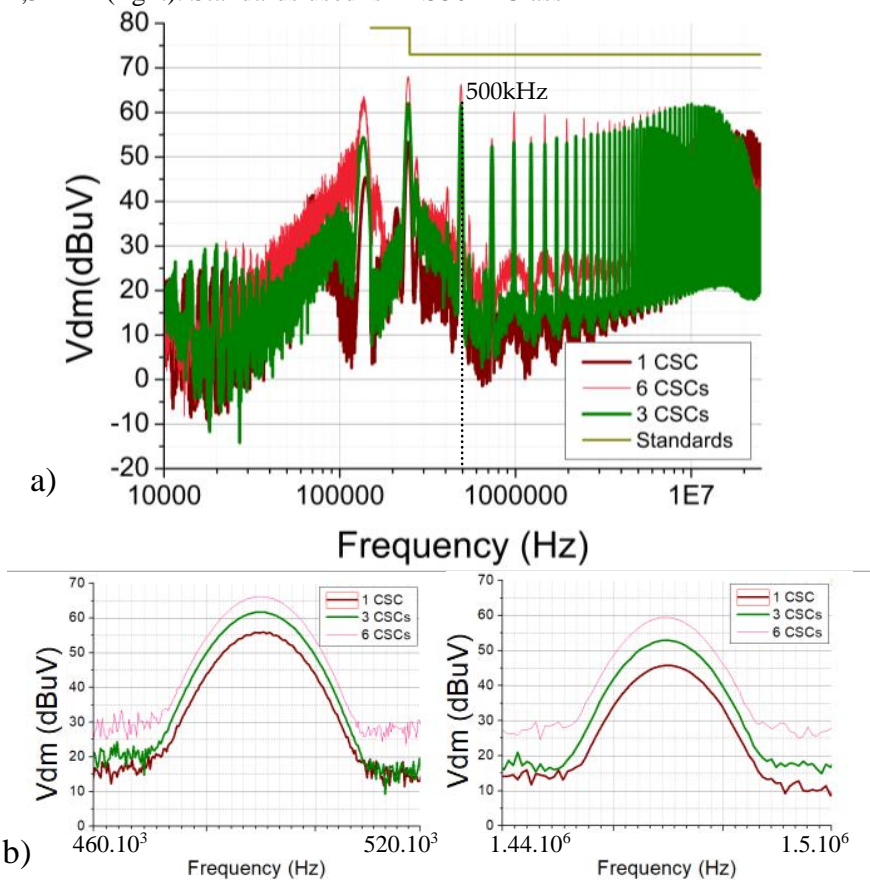

Fig. 11. Differential mode EMC spectrum of one, three and six CSCs in series association with only input filter $\mathrm{C}_{\text {in }}$ distributed on each CSC- LISN $\mathrm{V}_{\mathrm{DM}}$ measurements with a) full frequency range b) focus on $500 \mathrm{kHz}$ (left) and $1.5 \mathrm{MHz}$ (right). Standards used is EN55022 Class A

Figure 11 are plotted the results for comparable measurements considered CSCs associated in series. This time, as expected, a cumulative effect can be observed on the magnitude of the first order add harmonics multiples of twice the switching frequency. This validates our theoretical analysis and shows that an EMI analysis is required after the interconnection of CSCs in series if only distributed first order filters are implemented.

The converter with three CSCs in series produces an harmonic magnitude vertically shifted by $9.5 \mathrm{~dB} \mu \mathrm{V}$ $(20 * \log (3))$ compared to the converter with only one CSC implemented. Similarly, the converter with six CSCs in series produces an harmonic magnitude shifter by $15 \mathrm{~dB} \mu \mathrm{V}$ $(20 * \log (6))$ compared to the converter with only one CSC. As explained in the analysis section, networking CSCs in parallel should not affect the EMC signature of a modular converter compared to the one of a single CSC. On the opposite side, this should be the case when networking CSCs in series. Adding a capacitive centralized filter in both cases should mitigate this difference as introduced before. Figure 12 presents the spectrum measurements for one and three CSCs associated in parallel and in series respectively including this time in the experiments a centralized filtering capacitor when several CSCs are associated. The filtering capacitor added has the same value as the one used in the distributed filter $\mathrm{C}_{\mathrm{f}}=$ $20 \mu \mathrm{F}$.

a)

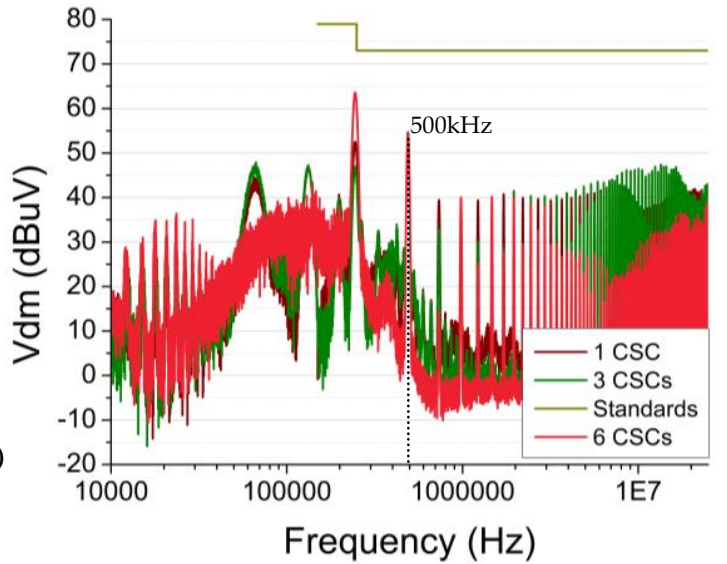

b)
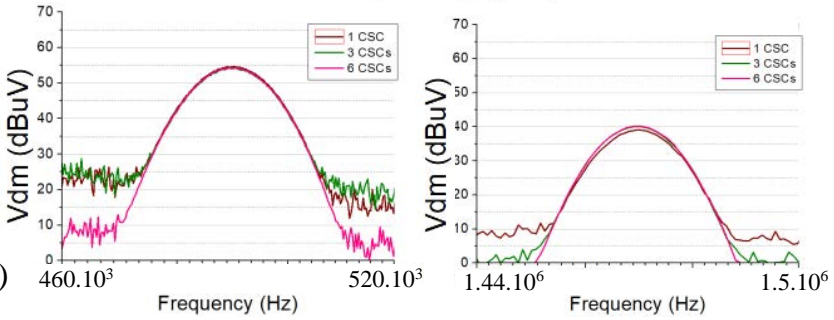

Fig. 12. Differential mode EMC spectrum of one CSC and three CSC in parallel association with filtering stage- LISN $V_{\mathrm{DM}}$ measurements with a) full frequency range b) focus on $500 \mathrm{kHz}$ (left) and $1.5 \mathrm{MHz}$ (right). Standards used is EN55022 Class A

Putting a filtering capacitor on the whole converter makes it possible to reach a networking which has no influence on EMC signature. The two figures 12 and 13 are showing it: there is almost a perfect fitting to one CSC signature whatever the association. This is consistent with the theory presented in this paper and it validated DM theoretical analysis.

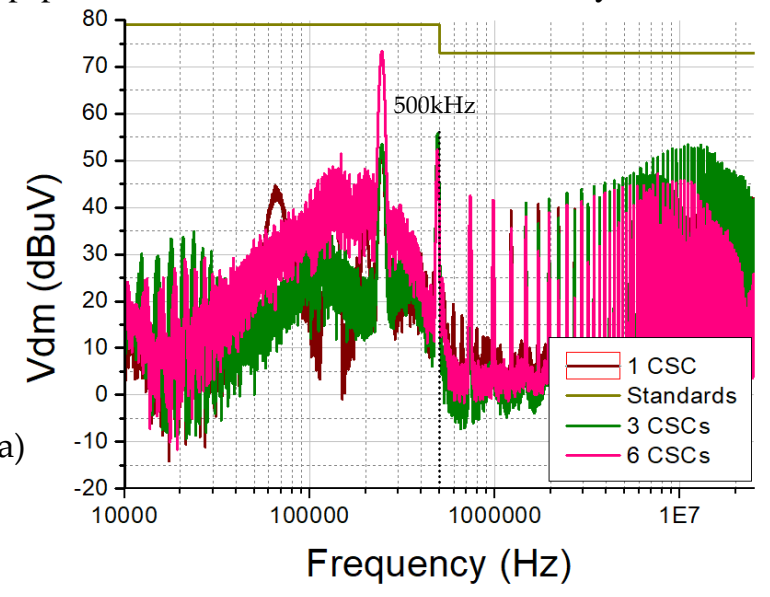


b)
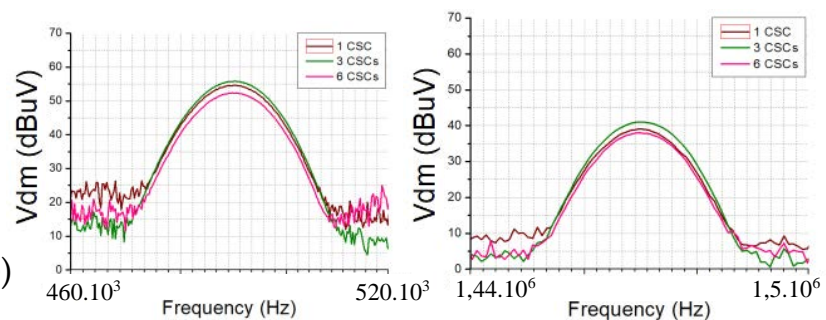

Fig. 13. Differential mode EMC spectrum of one CSC and three CSC in series association with filtering stage- LISN $V_{D M}$ measurements with a) full frequency range b) focus on $500 \mathrm{kHz}$ (left) and $1,5 \mathrm{MHz}$ (right). Standards used is EN55022 Class A

\section{CONCLUSION}

The EMC aspect of a modular converter is a delicate task to manage. Networking provides the ability to distribute the EMC filter to each CSC. It is indeed easier to distribute a filtering by CSC and thus to avoid a sizing according to the association. The theoretical part of this paper highlights the different options for filtering DM current. Some usual filter topologies have been studied here and their benefits are shown here. The solution adopted is a capacitor for the distributed filter and another capacitor for the globalized filter. The test setup and test results are finally shown and validate the theory. Moreover, our converters comply with standards EN55022. The way our converters and the filter blocks are designed allows us to comply with standards whatever the number of CSC interconnected. Therefore, in-depth work at certain frequencies is required. For example, the harmonic at switching frequency is still present and should not be here because of the $\mathrm{H}$ bridge. Some more complex filtering blocks are currently studied and ready to be tested. It necessitates otherwise studying common mode EMC. These research prospects will be developed in the future. This paper is a successful first step in EMC management in modular converters.

\section{REFERENCES}

[1] T. Ericsen and A. Tucker, "Power Electronics Building Blocks and potential power modulator applications," Conference Record of the Twenty-Third Int. Power Modulator Symposium, Rancho Mirage, CA, 1998, pp.12-15

[2] T. Ericsen, Y. Khersonsky, and P.K. Steimer, "PEBB Concept Applications in High Power Electronics Converters", Conf. Rec. IEEE PESC 2005, pp. $2284-2289$

[3] L. Kerachev et al., "A New Step Towards the Power Electronics Design Automation," PCIM Europe 2017; International Exhibition and Conference for Power Electronics, Intelligent Motion, Renewable Energy and Energy Management, Nuremberg, Germany, 2017, pp. 1-8.

[4] F. Krismer, "Modeling and optimization of bidirectional dual active bridge DC-DC converter topologies," Ph.D. dissertation, Power Electron. Syst.Lab., ETH Zurich, Zurich, Switzerland, 2010

[5] D. N. Heirman, "A History of the Evolution of EMC Regulatory Bodies and Standards", 16th International Zurich Symposium on Electromagnetic Compatibility, February 2005

[6] C. Gautier, et al, "EMC behavior of PWM inverter structure based on coupled interleaved cells using Intercell Transformers," Proceedings of the 2011 14th European Conf. on Power Electronics and Applications, Birmingham, 2011, pp. 1-10.

[7] F. Forest, et al, "Design and Comparison of Inductors and Intercell Transformers for Filtering of PWM Inverter Output," in IEEE Transac. on Power Electronics, vol. 24, no. 3, pp. 812-821, March 2009.
[8] M. Delhommais, et al, "Design by optimization of power electronics converter including EMC constraints," 2016 Inter. Symposium on Electromagnetic Compatibility - EMC EUROPE, Wroclaw, 2016, pp. 182-187.

[9] J. M. Choe et al., "Controller and EMI filter design for modular front-end solid-state transformer," 2018 IEEE Applied Power Electronics Conference and Exposition (APEC), San Antonio, TX, 2018, pp. 188192.

[10] F. Krismer, "Modeling and optimization of bidirectional dual active bridge DC-DC converter topologies," Ph.D. dissertation, Power Electron. Syst.Lab., ETH Zurich, Zurich, Switzerland, 2010

[11] F. Sarrafin-Ardebili, et al, "Capacitive Coupling for High Voltage Ratio Power Transfer in Multi-Cell Converters Based on GaN HFETs," CIPS 2016; 9th Inter.Conf. on Integrated Power Electronics Systems, Nuremberg, 